08.2;04.1

\title{
Получение тонких пленок графита на диэлектрической подложке с помощью гетероэпитаксиального синтеза
}

\author{
(С) И.А. Сорокин ${ }^{1,2}$, Д.В. Колодко ${ }^{1,2}$, В.А. Лузанов ${ }^{1}$, Е.Г. Шустин ${ }^{1}$ \\ ${ }^{1}$ Фрязинский фрилиал Института радиотехники и электроники им. В.А. Котельникова РАН, Фрязино, Московская обл., \\ Россия \\ ${ }^{2}$ Национальный исследовательский ядерный университет „МИФИ“, Москва, Россия \\ E-mail: iasorokin@mail.ru
}

Поступило в Редакцию 19 декабря 2019г.

В окончательной редакции 28 февраля 2020 г.

Принято к публикации 2 марта 2020г.

\begin{abstract}
Представлены результаты отработки методики получения тонких графитовых пленок на диэлектрической подложке методом отжига структуры $\mathrm{Al}_{2} \mathrm{O}_{3}(0001) / \mathrm{Ni}(111) / t a-\mathrm{C}$. Методика основана на каталитическом разложении углеводородов на поверхности монокристаллической пленки металла-катализатора на диэлектрической подложке и последующей диффузии и кристаллизации углерода между металлической пленкой и подложкой. После химического травления металлической пленки получается тонкая графитовая пленка с низкой плотностью дефектов кристаллической структуры на диэлектрической подложке.
\end{abstract}

Ключевые слова: графен, гетероэпитаксия, металл-катализатор, синтез, никель, диэлектрическая подложка.

DOI: 10.21883/PJTF.2020.10.49431.18160

Графен из-за его уникальных физико-химических свойств представляет собой перспективный функциональный материал, в частности, для применения в наноэлектронике и фотонике. Наиболее привлекательными свойствами графена являются высокая подвижность носителей заряда, регулируемая ширина запрещенной зоны, высокая электро- и теплопроводность, зависимость электронных характеристик от наличия на поверхности графена присоединенных радикалов различной природы. Основные свойства и приложения - как уже реализованные, так и потенциальные - представлены, например, в обзорах [1-3].

Пленки графена обычно получаются методом синтеза при крекинге газообразных углеводородов на поверхности металла-катализатора CVD- или PECVD-способом. В работах [4-8] описан альтернативный метод: синтез графена осуществляется при растворении и диффузии углерода из твердых углеродных или углеводородных покрытий в металле-катализаторе при отжиге и его кристаллизации при остывании. Данный способ имеет явное преимущество, состоящее в том, что графен, получающийся на интерфейсе металл-никель, после химического стравливания металла оказывается на диэлектрической подложке.

Настоящая работа продолжает описанные в [8] исследования по разработке способа получения наноразмерных пленок графита (одно- и многослойного графена) с минимальной плотностью структурных дефектов.

Одной из наиболее подходящих поверхностей для осуществления гетероэпитаксиального синтеза графена является поверхность монокристалла никеля (111), имеющая необходимую симметрию кристалла, а также минимальное рассогласование постоянной решетки со структурой монокристалла графена. Для формирования монокристаллических пленок никеля на сапфире мы использовали технологию, описанную ранее в [9].

В качестве подложки для получения пленок $\mathrm{Ni}(111)$ использовались монокристаллы сапфира (0001) размером $5 \times 5 \mathrm{~mm}$. Выбор материала подложки обусловлен близостью постоянных кристаллических решеток сапфира и никеля (0.216 и $0.215 \mathrm{~nm}$ соответственно) [10,11], определяющей возможность гетероэпитаксиального синтеза никелевой пленки на сапфире. Также сапфир обладает высокой теплопроводностью $(34.6 \mathrm{~W} /(\mathrm{m} \cdot \mathrm{K})$, что важно в процессах отжига.

Гетероэпитаксиальные пленки никеля толщиной $400 \mathrm{~nm}$ осаждались на сапфир методом магнетронного распыления. Полученные пленки $\mathrm{Ni}(111)$ имеют высокую степень совершенства кристаллической структуры (с полушириной кривой качания $\left.<0.3^{\circ}\right)$. Рентгеноструктурный анализ полученных слоев проводился с помощью автоматизированного двухкристального рентгеновского дифрактометра ДРОН-3, работающего по схеме Брэгга-Брентано.

Для осуществления эпитаксиального синтеза графена методом отжига необходимо обеспечить минимальную концентрацию неупорядоченных границ зерен и дефектов поверхности подложки, на которую производится осаждение углеродных пленок. Подобные дефекты являются активными каталитическими центрами зарождения графена $[12,13]$, что приводит к формированию неоднородных поликристаллических пленок. Метод [9] позволяет минимизировать двойникование никеля, типичное для формирования монокристаллов металлов с кубической гранецентрированной решеткой на сапфировых подложках $[9,14]$. 

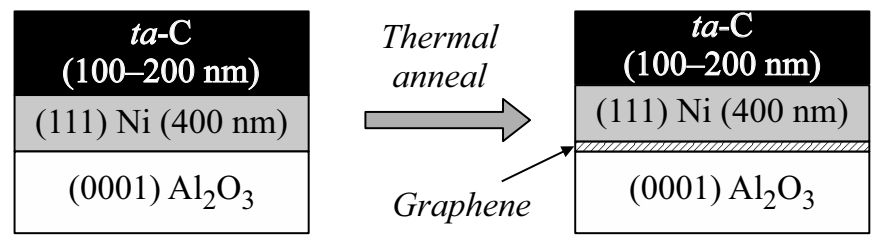
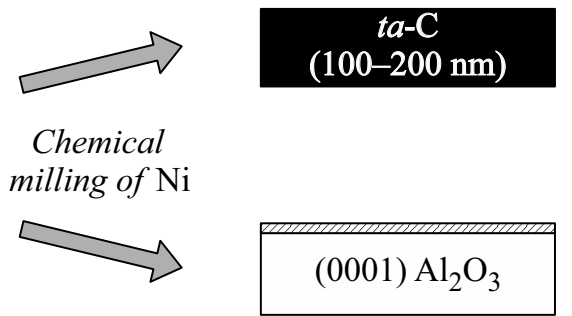

Рис. 1. Схема цикла получения наноразмерной пленки графита на сапфировой подложке.

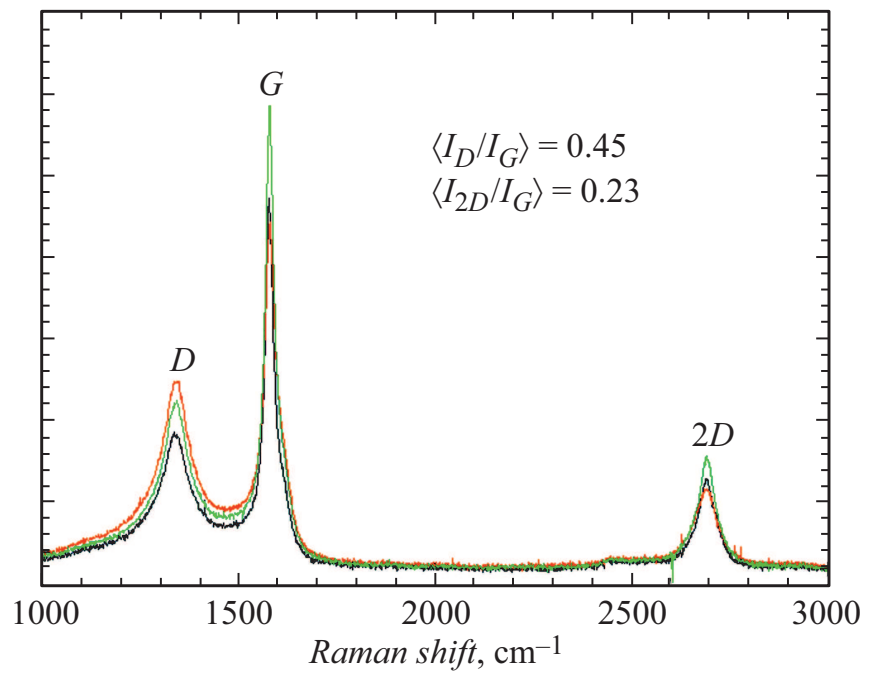

Рис. 2. СКР поверхности углеродной пленки на сапфировой подложке. Отжиг: $700^{\circ} \mathrm{C}, 3 \mathrm{~h}$.

Полученные образцы $\mathrm{Al}_{2} \mathrm{O}_{3} / \mathrm{Ni}$ отжигались в атмосфере водорода (давление $1 \mathrm{~Pa}$, температура $400^{\circ} \mathrm{C}$ ) в вакуумной камере для восстановления поверхности никеля. Далее проводилось плазмохимическое осаждение нанокристаллического графита или алмазоподобного углерода - ta-C (тетраэдрический аморфный углерод) в разряде с полым катодом [15]. В качестве плазмообразующего газа использовался аргон с добавлением пропана. Толщина углеродной пленки варьировалась в интервале $100-200 \mathrm{~nm}$. Форма спектров комбинационного рассеяния (СКР) [15] соответствует спектру нанокристаллического графита [16]. Среднее значение соотношения $\left\langle I_{D} / I_{G}\right\rangle$ составило 0.9. Однородность толщины, морфологии и кристаллической структуры пленки была подтверждена с помощью измерений СКР и метода атомно-силовой микроскопии [15].

Отжиг полученных образцов проводился в вакуумном стенде на базе высоковакуумного поста Pfeiffer Vacuum HiCube 80. На рис. 1 представлена схема получения тонкой графитовой пленки на диэлектрической подложке.

Вакуумная камера стенда откачивалась до предельного остаточного вакуума $\left(10^{-5} \mathrm{~Pa}\right)$. Далее вольфрамовым нагревателем в керамической оболочке производился нагрев образца до необходимой температуры. Контроль температуры осуществлялся встроенной термопарой $K$-типа. После отжига образец остывал со скоростью $<1^{\circ} \mathrm{C} / \mathrm{s}$ при предельном остаточном давлении в камере.

При отжиге происходит растворение материала углеродной пленки и диффузия углерода к поверхности никеля. Одновременно с этим происходит кристаллизация углерода между никелем и сапфиром по всей площади подложки с формированием графитовой структуры.

Толщина получаемых при этом пленок графита может контролироваться условиями отжига: температурой (растворимостью углерода в никеле), количеством исходного углерода [5] и временем (количеством диффундировавшего углерода) $[4,6,7]$. После отжига металлический слой химически стравливался с помощью водного раствора хлорного железа. При растворении никеля одновременно удаляется напыленный на него углерод. На поверхности сапфира остается сформированная при отжиге и остывании пленка углерода.

Кристаллическая структура получаемых углеродных пленок между металлом и сапфиром исследовалась сквозь сапфир с помощью рамановского микроскопа РамМикс М532 (ООО „ИнСпектр“, Черноголовка, Россия), включающего в себя рамановский спектрометр EnSpectr R532 (длина волны лазера $532 \mathrm{~nm}$, спектральный диапазон $150-4000 \mathrm{~cm}^{-1}$ ) и микроскоп Olympus CX-41 с оптической системой, адаптированной под измерения на пропускание и отражение. Изучение динамики растворения углерода в никеле и формирования тонких слоев проводилось в рамках последовательных измерений СКР после каждого цикла отжига образцов.

Отжиг образцов $\mathrm{Al}_{2} \mathrm{O}_{3}(0001) / \mathrm{Ni}(111) / t a-\mathrm{C}$ проводился при температурах $600-800^{\circ} \mathrm{C}$ в течение $1-8 \mathrm{~h}$. Нижний порог температуры обусловлен температурой распада карбида никеля, возникновение которого на поверхности металла при более низкой температуре является препятствием для диффузии углерода сквозь никель [17]. Измерение СКР сквозь сапфир показало, что в промежутке между никелем и сапфиром формируется графитовая пленка. На рис. 2 представлены примеры СКР, измеренные в нескольких точках одного образца после стравливания металлической пленки.

Сигнал СКР практически не меняется в рамках одного образца. Полученные соотношения пиков СКР углерода $\left(\left\langle I_{D} / I_{G}\right\rangle=0.45,\left\langle I_{2 D} / I_{G}\right\rangle=0.23\right)$ свидетельствуют о наличии графитовой пленки с толщиной, существенно 

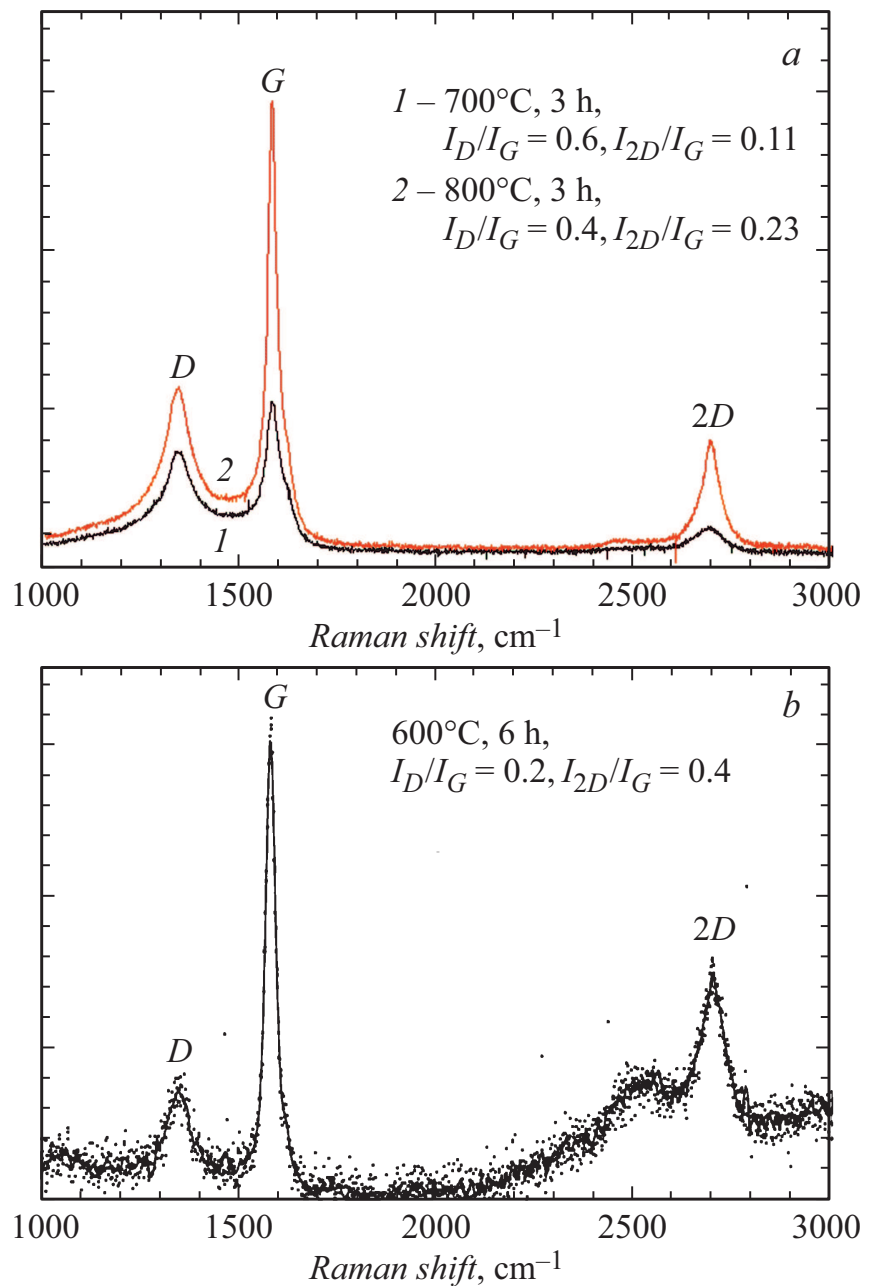

Рис. 3. СКР поверхности тонкой углеродной пленки на диэлектрической подложке для различных температур отжига: $a-700$ и $800^{\circ} \mathrm{C}, b-600^{\circ} \mathrm{C}$.

превышающей один атомарный слой. На рис. 3, $a$ представлены СКР графитовых пленок для двух температур отжига при одинаковой длительности отжига.

При увеличении температуры отжига при одинаковом времени экспозиции интенсивность пиков возрастает из-за незначительного увеличения растворимости углерода в никеле (с $3 \cdot 10^{26} \mathrm{~m}^{-3}$ для $700^{\circ} \mathrm{C}$ до $4 \cdot 10^{26} \mathrm{~m}^{-3}$ для $800^{\circ} \mathrm{C}$ ). Отношение $I_{D} / I_{G}$, характеризующее плотность дефектов кристаллической структуры пленки, уменьшается (с 0.6 до 0.4 ), $I_{2 D} / I_{G}$ растет (с 0.11 до $0.23)$. Последующие отжиги при меньшей температуpe $\left(600^{\circ} \mathrm{C}\right)$ способствуют формированию графита со все более совершенной кристаллической структурой (рис. $3, b)$, как и в $[8]$, где $I_{D} / I_{G}$ и $I_{2 D} / I_{G}$ достигают 0.06 и 0.27 соответственно.

Таким образом, в работе апробирована методика получения тонких графитовых пленок на диэлектрической подложке методом отжига структуры $\mathrm{Al}_{2} \mathrm{O}_{3}(0001) / \mathrm{Ni}(111) / t a-\mathrm{C}$. Методика основана на каталитическом разложении углеводородов на поверхности мо- нокристалла металла-катализатора и последующей диффузии и кристаллизации углерода на обратной стороне металлической пленки. После химического травления металлической пленки получается тонкая графитовая пленка с низкой плотностью дефектов кристаллической структуры на диэлектрической подложке. Поверхность полученных углеродных пленок с толщиной, существенно превышающей один атомарный слой, равномерна в рамках используемых образцов $(5 \times 5 \mathrm{~mm})$. Варьирование температуры и времени отжига, а также исходного количества углерода в дальнейшем позволит контролировать количество участвующего в формировании атомарных слоев углерода.

\section{Финансирование работы}

Работа выполнена в рамках государственного задания и частично поддержана Российским фондом фундаментальных исследований (проекты РФФИ № 18-38-00884, 19-07-00432).

\section{Конфликт интересов}

Авторы заявляют, что у них нет конфликта интересов.

\section{Список литературы}

[1] Wu Y., Jenkins K.A., Valdes-Garcia A., Farmer D.B., Zhu Y., Bol A.A., Dimitrakopoulos Ch., Zhu W., Xia F., Avouris Ph., Lin Y.-M. // Nano Lett. 2012. V. 12. N 6. P. 3062-3067. DOI: $10.1021 / \mathrm{nl} 300904 \mathrm{k}$

[2] Bonaccorso F., Lombardo A., Hasan T., Suna Zh., Colombob L., Ferraria A.C. // Mater. Today. 2012. V. 15. N 12. P. 564-589. DOI: $10.1016 / \mathrm{S} 1369-7021(13) 70014-2$

[3] Randviir E.P., Brownson D.A.C., Banks C.E. // Mater. Today. 2014. V. 17. N 9. P. 426-432. DOI: 10.1016/j.mattod.2014.06.001

[4] Peng Z., Yan Z., Sun Z., Tour J.M. // ACS Nano. 2011. V. 5. N 10. P. $8241-8247$. DOI: $10.1021 / \mathrm{nn} 202923 \mathrm{y}$

[5] Zheng M., Takei K., Hsia B., Fang H., Zhang X., Ferralis N., Ko H., Chueh Y.-L., Zhang Y., Maboudian R., Javey A. // Appl. Phys. Lett. 2010. V. 96. N 6. P. 063110. DOI: $10.1063 / 1.3318263$

[6] Xu M., Fujita D., Sagisaka K., Watanabe E., Hanagata N. // ACS Nano. 2011. V. 5. N 2. P. 15221528. DOI: $10.1021 / \mathrm{nn} 103428 \mathrm{k}$

[7] Sun Z., Yan Z., Yao J., Beitler E., Zhu Y., Tour J.M. // Nature. 2011. V. 471. N 7336. P. 124. DOI: $10.1038 /$ nature09804

[8] Шустин Е.Г., Исаев Н.В., Лузанов В.А., Темирязева М.П. // ЖТФ. 2017. Т. 87. В. 7. С. 10531056. DOI: 10.21883/JTF.2017.07.44677.2006 [Пер. версия: $10.1134 / \mathrm{S} 1063784217070210]$.

[9] Luzanov V.A., Kotelyanskii I.M., Shustin E.G. // J. Commun. Technol. Electron. 2017. V. 62. N 7. P. 820-821. DOI: $10.1134 / \mathrm{S} 1064226917060134$

[10] Rahman M., Boggs Z., Neff D., Norton M. // Langmuir. 2018. V. 34. N 49. P. 15014-15020. DOI: $10.1021 /$ acs.langmuir.8b01851 
[11] Nakanishi S., Horiguchi T. // Jpn. J. Appl. Phys. 1981. V. 20. N 3. P. L214-L216. DOI: 10.1143/jjap.20.1214

[12] Ismach A., Chou H., Ferrer D.A., Wu Y., McDonnell S., Floresca H.C., Covacevich A., Pope C., Piner R., Kim M.J., Wallace R.M., Colombo L., Ruoff R.S. // ACS Nano. 2012. V. 6. N 7. P. 6378-6385. DOI: 10.1021/nn301940k

[13] Baraton L., He Z.B., Lee C.S., Cojocaru C.S., Châtelet M., Maurice J.-L., Lee Y.H., Pribat D. // Europhys. Lett. 2011. V. 96. N 4. P. 46003. DOI: 10.1209/0295-5075/96/46003

[14] Фомин Л.А., Маликов И.В., Винниченко В.Ю., Калач К.М., Пяткин С.В., Михайлов Г.М. // Поверхность. Рентгеновские, синхротронные и нейтронные исследования. 2008. № 2. С. 27-32 [Пер. версия: 10.1007/s11700-008-1015-z].

[15] Сорокин И.А., Колодко Д.В., Шустин Е.Г. // ЖТФ. 2018. T. 88. B. 8. C. $1191-1194$.

DOI: 10.21883/JTF.2018.08.46307.2629 [Пер. версия: 10.1134/S1063784218080194].

[16] Chu P.K., Li L. // Mater. Chem. Phys. 2006. V. 96. N 2-3. P. 253-277. DOI: 10.1016/j.matchemphys.2005.07.048

[17] Lahiri J., Miller T.S., Ross A.J., Adamska L., Oleynik I.I., Batzill M. // New J. Phys. 2011. V. 13. P. 025001 (1-19). DOI: $10.1088 / 1367-2630 / 13 / 2 / 025001$ 